\title{
DETECTION OF BARTONELLA HENSELAE IN DEFIBRINATED SHEEP BLOOD USED FOR CULTURE MEDIA SUPPLEMENTATION
}

\author{
Marina Rovani Drummond ${ }^{*}$, Luiza H. U. Pitassi ${ }^{1}$, Bruno G. Lania ${ }^{1}$, Silvio R. C. dos Santos ${ }^{2}$, Rovilson Gilioli ${ }^{2}$, Paulo E. N. \\ F. Velho ${ }^{1}$
}

${ }^{1}$ Departamento de Medicina Interna, Faculdade de Ciências Médicas, Universidade Estadual de Campinas, Campinas, SP, Brasil; Centro Multidisciplinar para Investigação Biológica, Universidade Estadual de Campinas, Campinas, SP, Brasil.

Submitted: December 13, 2009; Returned to authors for corrections: October 06, 2010; Approved: January $13,2011$.

\begin{abstract}
Bartonella henselae was detected in defibrinated sheep blood employed in supplementing a selective bacteria culture medium by nested PCR. We recommended that highly sensitive technical tests be run to ensure a sterile culture medium for Bartonella spp. isolation, since infected blood samples used in preparation could lead to false-positive results.
\end{abstract}

Key words: Bartonella, Culture Media, False Positive Reactions, Polymerase Chain Reaction, Sheep-Blood Contamination.

The Bartonella genus comprises many species and is responsible for a large number of emerging and reemerging infectious diseases. They are small and fastidious Gramnegative bacilli whose growth is favored by blood enriched media and an atmosphere supplemented with $5 \% \mathrm{CO}_{2}(1)$. Bartonella spp. infect pets, besides several other mammals, including rabbits, horses and sheep. They are of zoonotic importance. Three species of Bartonella are associated with the largest number of clinical manifestations in humans: Bartonella bacilliformis (agent of Oroya fever and verruga peruana), Bartonella henselae (agent of cat scratch disease, bacillary angiomatosis, bacillary peliosis, endocarditis, and septicemia), and Bartonella quintana (agent of trench fever, bacillary angiomatosis, bacteremia, and endocarditis) $(6,9)$. Of these, Bartonella henselae is the bacterium that is more often related with human disease.

Aiming to isolate a wild strain of $B$. henselae in Brazil, to be employed in the local production of antigens for serological tests, we began a study for culturing samples of stray cats. Bemis and Kania (2) have reported finding Bartonella sp. contamination in the defibrinated sheep blood, used in the preparation of culture media in their laboratory and Maggi et al. (8) also found that some batches of commercial sheep blood contained Candidatus Bartonella melophagi DNA.

The culture medium chosen for Bartonella spp. isolation was Bordet Gengou Agar Base enriched with $30 \%$ of defibrinated sheep blood. Blood samples from cats were sown and two negative controls were performed: a plate with solid

*Corresponding Author. Mailing address: Dermatology Division, Department of Internal Medicine, School of Medical Sciences, UNICAMP, Rua Tessália Vieira Camargo, 126 Barão Geraldo, Campinas- SP Brazil. Zip code: 13084-971, Mailbox: 6111.; Tel.: 55-19-35217602.; E-mail: marina.rovani@ gmail.com 
medium enriched with sheep blood, without any sown sample, and another control sown with a sample of defibrinated blood as received from the supplier. Both were incubated at $35^{\circ} \mathrm{C}$ in environment with $5 \% \mathrm{CO}_{2}$ water saturated atmosphere for 45 days. This procedure was repeated in ten batches of defibrinated sheep blood acquired from the same supplier. It is important to clarify that each batch of defibrinated sheep blood is collected from a single animal by the supplier, thus allowing for lot traceability. All of the supplier's sheep live in same conditions and may be exposed to these bacteria. After 45 days, none solid media plates presented any bacterial growth.

In addition, a sample of each batch of sheep blood was aseptically collected, as soon as it arrived from the supplier (prior to preparing the culture medium), and submitted to PCR to verify the absence of contamination by $B$. henselae, the Bartonella species that most frequently infects cats. DNA was extracted from the blood using the QIAamp ${ }^{\circledR}$ DNA Mini kit (Qiagen) and was tested with specific nested PCR for the region that encodes for the FtsZ bacterial cell division protein of $B$. henselae. The outer primers used in the first round of nested PCR amplification were described by Kelly et al. (5) and the inner primers were designed by Kawasato (4) with the following sequences: forward primer (BHS) CAAAACGGTTGGAGAGCAGT and reverse primer (BHA) CGCCTGTCATCTCATCAAGA. There was amplification in the nested-PCR second round in one sample of ten batches. This reaction was repeated with another aliquot of positive defibrinated sheep blood from the same batch and the positive result was confirmed.

The region obtained with these primers just amplified $B$. henselae sequence and there is no B. melophagi either another Bartonella specie sequences correspondent in GenBank. To confirm that DNA amplified obtained by nested-FtsZ PCR was really from B.henselae, the product was submitted an automated DNA sequencing. This technique showed that the fragment was $99 \%$ homologous with $B$. henselae Houston 1 strain (GenBank accession number BX897699).
Thus, bacterial contamination was proven despite negative culture results. The blood supplier's quality control tests are limited to readings performed only 48 hours after sowing the culture enriched medium with the blood to be tested - which is insufficient time for the growth of this bacterium. Testing for Bartonella requires extended incubation periods, since its growth may take over 40 days to be detectable (7). Culture negatives results can be explained since bacteria could be inactive. Another possibility is that prime isolation of Bartonella spp. can be extremely difficult. (3)

The bacteremia diagnosis caused by Bartonella spp. is routinely based on isolation of bacterium in culture media enriched with blood and/or PCR of tissue, blood or liquid medium that is also often enriched with blood. Blood from rabbits, sheep or horses used to do that could conducive to false-positive culture results. It could be more significant in blood enriched liquid culture media than solid ones because it can result in false positive isolations and PCRs.

In light of our finding, we recommended that highly sensitive molecular technical tests be run to control the blood used in preparing Bartonella spp. culture medium as supported by Bemis and Kania (2) and Maggi et al. (8). To date we lack diagnostic tests with sufficient sensitivity to rule out the Bartonella spp. infection and efforts should be made to standardize better techniques that allow us quick and safe diagnosis.

\section{REFERENCES}

1. Anderson, B.E.; Neuman, M.A. (1997). Bartonella spp. as emerging human pathogens. Clin. Microbiol. Rev. 10, 203-219.

2. Bemis, D.A.; Kania, A.S. (2007). Isolation of Bartonella sp. from sheep blood. Emerg. Infect. Dis. 13(10), 1565-1567.

3. Duncan A.W.; Maggi R.G.; Breitschwerdt E.B. (2007) A combined approach for the enhanced detection and isolation of Bartonella species in dog blood samples: pre-enrichment liquid culture followed by PCR and subculture onto agar plates. J Microbiol Methods. 69, 273-281.

4. Kawasato, K.H. Padronização de sistemas de dupla amplificação para detecção de DNA de Bartonella henselae em casos suspeitos de bartonelose humana. São Paulo, 2009, (M.D. Thesis. Faculdade de 
Ciências Médicas. USP).

5. Kelly, T.M.; Padmalayam, I.; Baumstark, B.R. (1998). Use of the Cell Division Protein FtsZ as a Means of Differentiating among Bartonella species. Clin. Diagn. Lab. Immunol. 5,766-772.

6. Lamas, C.; Curi, A.; Bóia, M.; Lemos, E. (2008). Human bartonellosis: seroepidemiological and clinical features with an emphasis on data from Brazil - a review. Mem. Inst. Oswaldo Cruz. 103(3), 221-235.

7. Maggi, R.G.; Harms, C.A.; Hohn, A.A.; Pabst, D.A.; McLellan, W.A.;
Walton, W.J.; Rotstein D. S.; Breitschwerdt E. B. (2005). Bartonella henselae in porpoise blood. Emerg. Infect. Dis. 11, 1894-1898.

8. Maggi, R.G.; Kosoy, M.; Mintzer, M.; Breitschwerdt, E.B. (2009). Isolation of Candidatus Bartonella melophagi from Human Blood. Emerg. Infect. Dis. 15, 66-68.

9. Pitassi, L.H.; Magalhães, R.F.; Barjas-Castro, M.L.; de Paula, E.V.; Ferreira, M.R.; Velho, P.E. (2007). Bartonella henselae infects human erythrocytes. Ultrastruct. Pathol. 31(6), 369-372. 